\title{
Energy efficiency improvement by implementation of the novel CRIMSON aluminium casting process
}

\author{
Mark Jolly ${ }^{1}$, Xiaojun Dai ${ }^{2}$, \\ ${ }^{1,2}$ School of Mechanical Engineering, University of Birmingham, \\ Edgbaston, Birmingham, B15 2TT, UK
}

Key words: energy saving, furnace, aluminium, casting, melting, CRIMSON

\begin{abstract}
Foundry engineers in the traditional foundry usually regard the quality of casting component as the most important issue and leave the energy saving or energy efficiency as the subsidiary one. This frequently causes disproportionate energy consumption as a result of the inefficient casting processes used and increases the production costs. This paper presents the novel CRIMSON aluminium casting process and compares its facility and melting process with traditional melt furnaces and aluminium alloy melting process. A real example is investigated to demonstrate quantitatively how the traditional foundry wastes energy and what the improvement of energy efficiency can be achieved using the new CRIMSON method. The results of this investigation will help the foundry engineer recognize the importance of energy saving and demonstrate how to use this new technology to reduce production costs and carbon footprint without decreasing the quality of the cast component.
\end{abstract}

\section{Introduction}

Aluminium melting in metal casting industry is an energy intensive process where it is estimated that the energy consumption is in the order of 6,000-17,000 MJ per tonne in using crucible and natural gas [1]. The main energy resources for aluminium casting in US are natural gas, electricity and coke [2]. In UK, most of the foundry use electricity, gas and oil as the fuel in the aluminium melting processes [3]. Due to the pressure of rising energy price and the limitation of strict environment protection legislation it is confirmed that under the right socioeconomic conditions efficiency optimisation of industrial process can be an important step toward increased industrial sustainability [4]. In metal casting industry the energy efficiency of a casting facility depends largely on the efficiency of its melting and heat treating performance. In association with the two performances, over $60 \%$ of the total process energy costs are represented in a typical casting facility [5] where there are huge opportunities for metal casting industry to adopt the best energy practices which will provide the great energy saving potential. To ameliorate the current processes for increasing energy efficiency will have a vital effect on reducing the production costs and promoting the competitiveness. For instance, by implementing some state of the art technologies such as the CRIMSON method in aluminium alloy casting will make use of such opportunities. 
The researchers and engineers from University of Birmingham and a local company, - N-Tec Ltd. have co-invented a patent CRIMSON (Constrained Rapid Induction Melting Single Shot Up-Casting) method. The objectives to develop this method are to decrease the energy consumption and to meliorate the casting quality within light-metal casting industry. After being successfully validated in the light-metal casting area, this method will be further applied in the other high end ferrous alloys. The methodology of the new method is that foundries, using an induction furnace, need only to melt the quantity of metal required to fill a single mould in a closed crucible rather than large batches that use unnecessary energy and create more rejects. As shown in Figure 1, the closed crucible, then, is transferred to a station and the melted metal is pushed up using a computer controlled anti-gravity filling method to fill the mould. Due to a characteristic of rapid melting, transfer and filling in the new method, the holding time of melted metal is minimised, a huge amount of energy saving is achieved and in the mean time the possibility of hydrogen absorption and formation of surface oxide film are decreased largely [6].
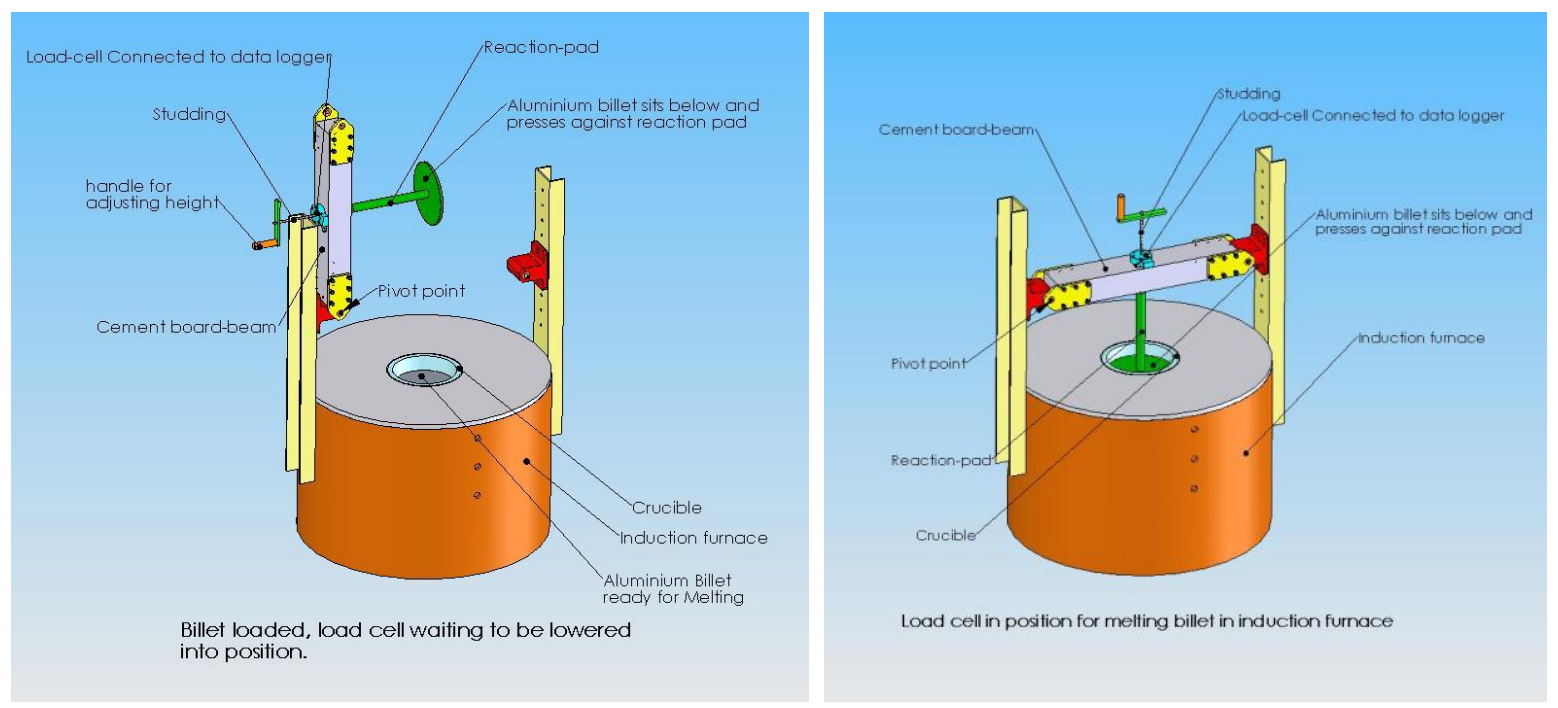

Figure 1 Crucible of the CRIMSON method

In this paper, the conventional melting process from one local company is investigated and it is compared with the new method. We mainly focus on the energy consumption of melting processes, other energy consumption issues will be investigated later in our research project. The calculation and analysis of energy consumption are completed to see what the difference between the current melting processes and the novel method. Thus, the potential energy saving for the new method can be found. This comparison is only one of a number being carried out under the aegis of an EPRSC project whereby four conventional casting processes will be benchmarked for their energy usage and scrap rates. 


\section{Investigation on the energy consumption of the conventional foundry and the new casting method}

Conventional melting process in Grainger \& Worrall ltd.

One of the workshops for producing high end casting components in Grainger \& Worrall (G\&W) Ltd. is currently using one type of melting furnace (Figure 2) with combining melting process where the primary melting area functioning like a stack melter and gas is used to preheat and melt aluminium ingot, then the melted aluminium alloy flowing along an inclined channel to a refining area where an electric resistance furnace is used. The refined liquid aluminium alloy is held in the electric resistance furnace. "Pouring" is carried out using an electromagnetic pump to pump the liquid metal to the mould where the process is called "Cosworth". In this workshop, there are two furnaces using this kind of combining melting processes for producing two types of aluminium alloys-A354 and A357. The capacity of both furnaces is 4 tonne. The holding time for each furnace is up to 4-5 days. The overheating temperature of A354 aluminium alloy is $760{ }^{\circ} \mathrm{C}$. The pouring temperature of the melted aluminium alloy is $700{ }^{\circ} \mathrm{C}$.

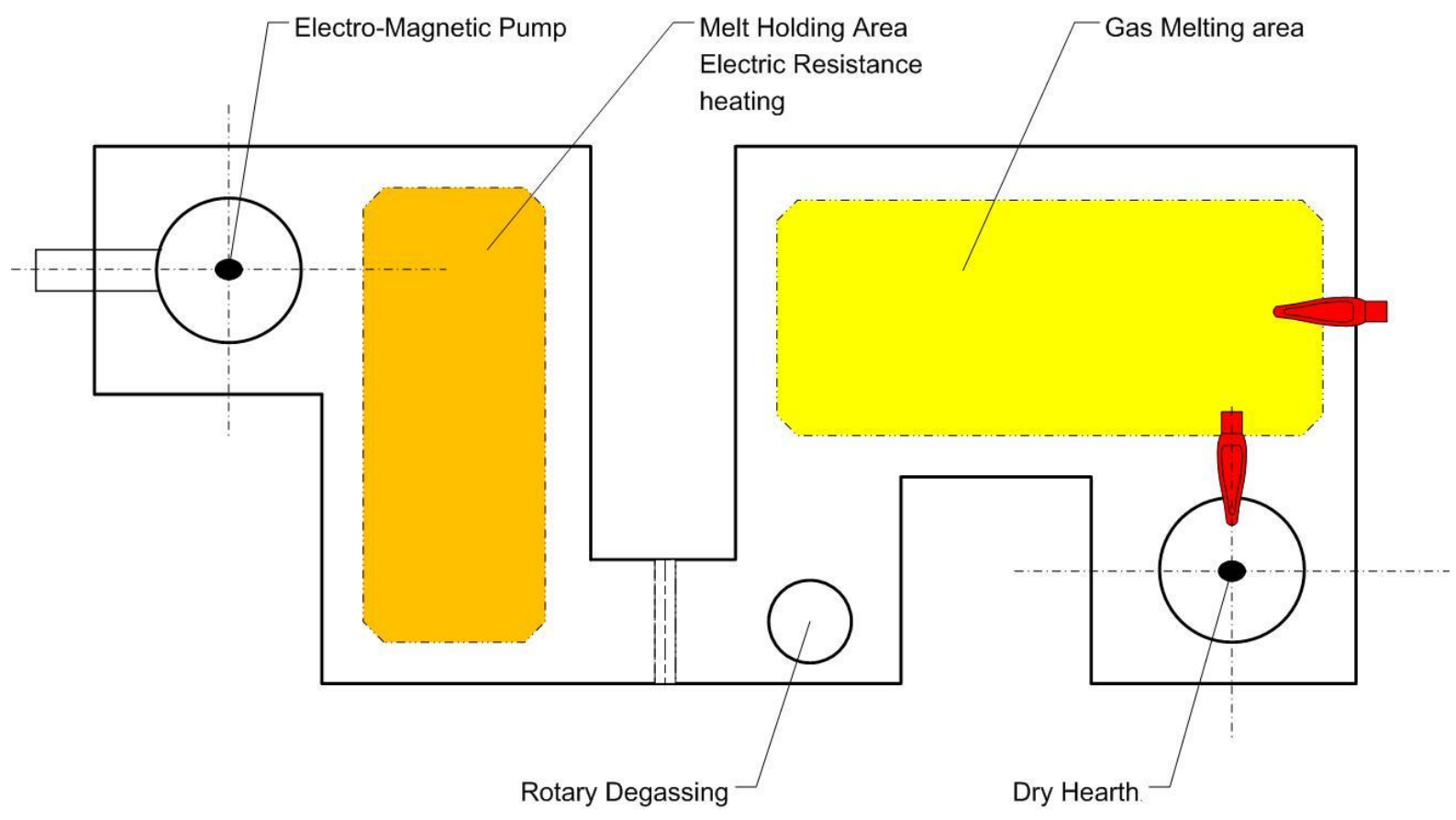

Figure 2 Schematic of the aluminium melting furnace in G\&W Ltd.

\section{The CRIMSON method}

The structure and layout of the novel casting process facility is indicated in Figure 3, where its functions and features are: 
- High power Induction furnace $(275 \mathrm{KW})$ : it is used to quickly heat and melt the metal to the required pouring temperature. Usually each time, a billet of the required size and calculated amount of metal is put in, also the composition of the billet should be consistent with the casting component that will be poured and produced;

- Up-caster: when the crucible with the melted metal inside is ready, it is moved and cramped in the right position in Up-caster and a mould is located on the top of pouring position, a piston in the Up-caster will raise and push the melted metal in the crucible into the mould;

- Computer-controlled operation table of the Up-caster: the movement of the piston in Up-caster is automatically controlled by the pre-programmed computer program;

- Mould transfer stop: after pouring, cooling down and solidification, the mould can be moved to the transfer stop, waiting for lifting and cleaning;

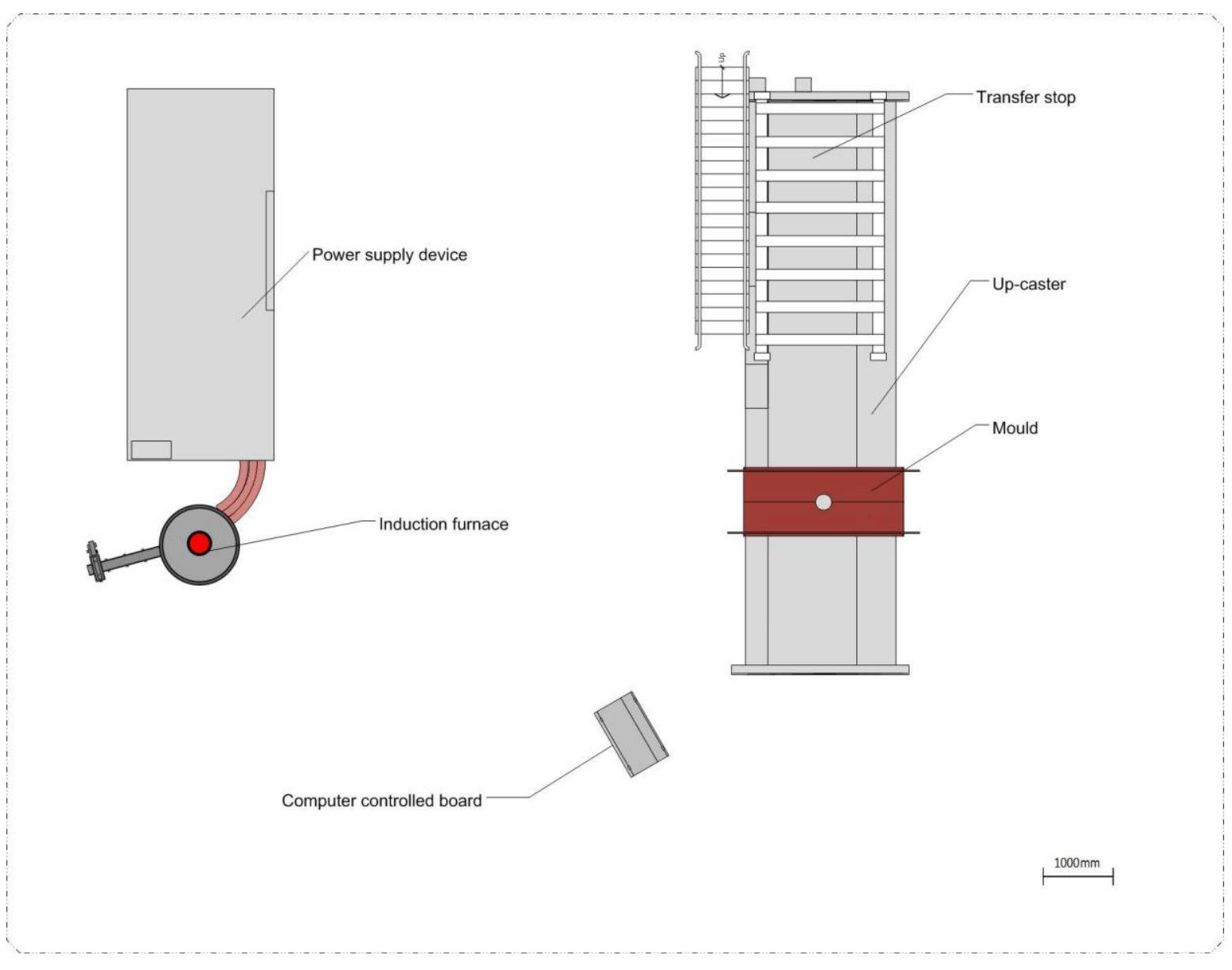

Figure 3 Schematic plan of the new casting process facility

\section{Casting sample}

A "Test bar" mould has been selected to use novel method to examine its energy consumption. The design of the "Test bar" with a runner system is shown in Figure 4 which has a profile of $530 \mathrm{~mm}$ length $\times 390 \mathrm{~mm}$ width $\mathrm{x} 100 \mathrm{~mm}$ height with a weight of $4 \mathrm{~kg}$ [7]. 
G\&W is currently using traditional sand casting processes to produce normal casting components and the Cosworth casting process is especially selected to produce high quality components.

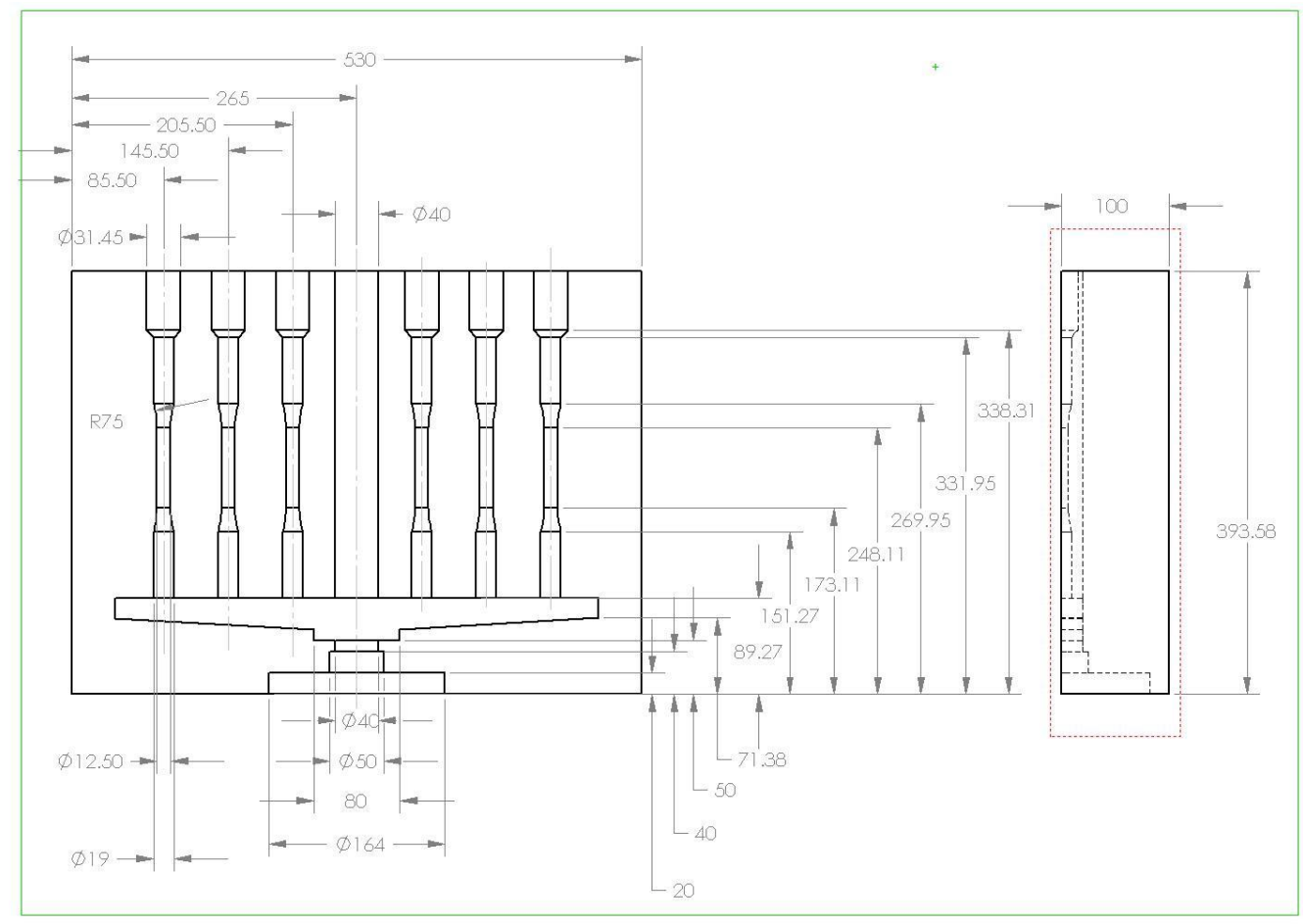

Figure 4 Structure of the "Test bar" with runner system [7].

\section{Thermodynamic analysis and energy efficiency}

\section{Thermodynamics analysis of the Furnace}

Aluminium melting processes in both crucible and induction furnace include complicated physical-chemical phenomena such as gas combustion, dross generation, phase change and heat transfer (radiation, conduction and convention). Some of the thermodynamic parameters can be measured easily such as temperature and pressure and in the mean time some parameters are difficult to measure such as the heat loss in the way of radiation and conventions. However, thermodynamic analysis of the energy balance during the melting process in a crucible or a furnace based on the experimental results is achievable [8]. These experimental results and the related thermodynamic analysis can be a reference to help casting industry to improve the energy efficiency and decrease the waste emission.

In this paper, an aluminium melting/holding furnace from a local company - G\&W ltd., and an induction furnace in the CRIMSON facility are used to implement the experiments and thermodynamic analysis. The schematics of energy balance in the aluminium melting furnace of G\&W ltd. and CRIMSON are shown in Figure 5 and Figure 6, respectively. The experiment and analysis of energy efficiency is based on the following assumptions: 
- The system assessed is at continuous steady state which includes fuel flow, air flow rate, melting rate, flue gas parameters and thermal conduction through furnace wall;

- The fuel and combustion products behave as ideal gas mixtures;

- The environment temperature and pressure are taken as standard $25^{\circ} \mathrm{C}$ and $1 \mathrm{~atm}$ respectively;

- The electric energy consumption is only applied to the part of electricity resistance heating or induction heating in furnaces, not applied to the motors and control devices which are neglected for the convenient calculation and simplicity;

- The natural gas composition is considered as pure propane due to the small amount of $\mathrm{N}_{2}, \mathrm{CO}_{2}, \mathrm{H}_{2} \mathrm{~S}$ and $\mathrm{H}_{2} \mathrm{O}$ included;

- The lost metal during drossing is neglected for the calculation simplicity.

The energy balance of the furnace at G\&W in Figure 5 can be expressed as [9]:

$$
\begin{aligned}
& E_{\text {in }}=E_{\text {out }} \\
& E_{\text {in }}=E_{\text {fuel }}+E_{\text {ingot }}+E_{\text {comb air }} \\
& E_{\text {out }}=E_{\text {melt }}+Q_{\text {mis }}=\left(E_{\text {ingot }}+\Delta E_{A l}\right)+Q_{\text {mis }} \\
& Q_{\text {mis }}=E_{\text {in }}-\Delta E_{A l} \\
& \eta=\Delta E_{\text {Al }} / E_{\text {fuel }}
\end{aligned}
$$

Where,

- $E_{\text {in }}$ is the energy input of the furnace system;

- $E_{\text {out }}$ is the energy output of the furnace system;

- $E_{f u e l}$ is the energy generated from fuel combustion;

- $E_{\text {ingot }}$ is the energy generated from aluminium ingot, here $E_{\text {ingot }}=0$;

- $E_{\text {comb air }}$ is the energy generated from combustion air, here $E_{\text {comb air }}=0$;

- $E_{\text {melt }}$ is the heat transferred to the melted metal;

- $\Delta E_{A l}$ is the energy variation of the metal from ingot to melted metal;

- $Q_{m i s}$ is all the energy loss during the melting process in a furnace chamber;

- $\quad \eta$ is the energy efficiency of the furnace at G\&W;

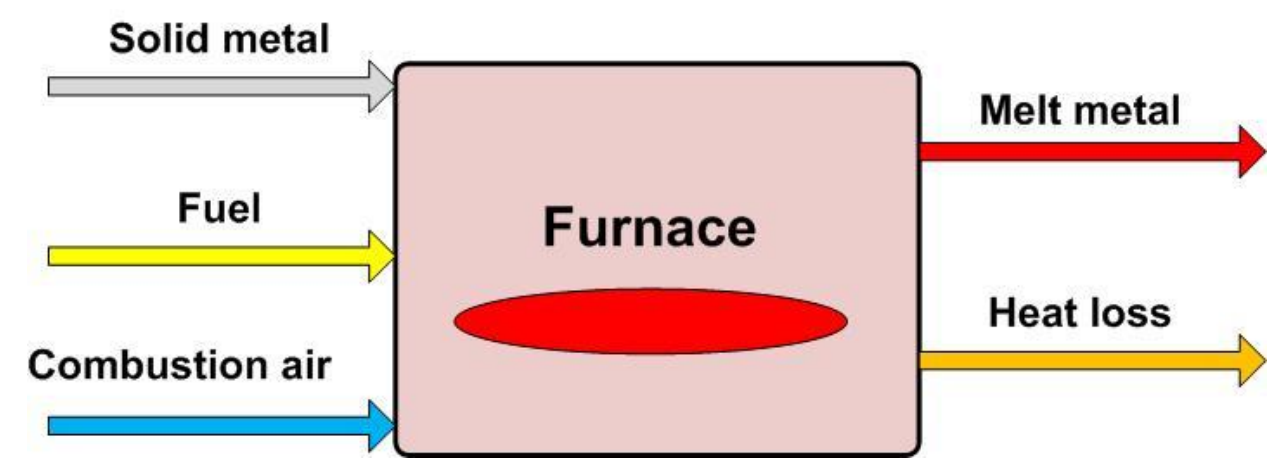

Figure 5 Schematic of energy balance in the aluminium melting furnace of $G \& W$ ltd. 
The energy balance of the induction furnace of the new process in Figure 6 can be expressed in a bit different type: equations 3.1 and 3.4 are the same; 3.2, 3.3 and 3.5 can be revised to as follows:

$$
\begin{array}{ll}
E_{\text {in }}=E_{\text {electricity }}+E_{\text {billet }} & 3.2^{*} \\
E_{\text {out }}=E_{\text {melt }}+Q_{\text {mis }}=\left(E_{\text {billet }}+\Delta E_{A l}\right)+Q_{\text {mis }} & 3.3^{*} \\
\eta_{c}=\Delta E_{\text {Al }} / E_{\text {electricity }} & 3.5^{*}
\end{array}
$$

Where,

- $E_{\text {electricity }}$ is the energy generated from electricity;

- $E_{\text {billet }}$ is the energy generated from aluminium billet, here $E_{\text {billet }}=0$;

- $\eta_{c}$ is the energy efficiency of the induction furnace;

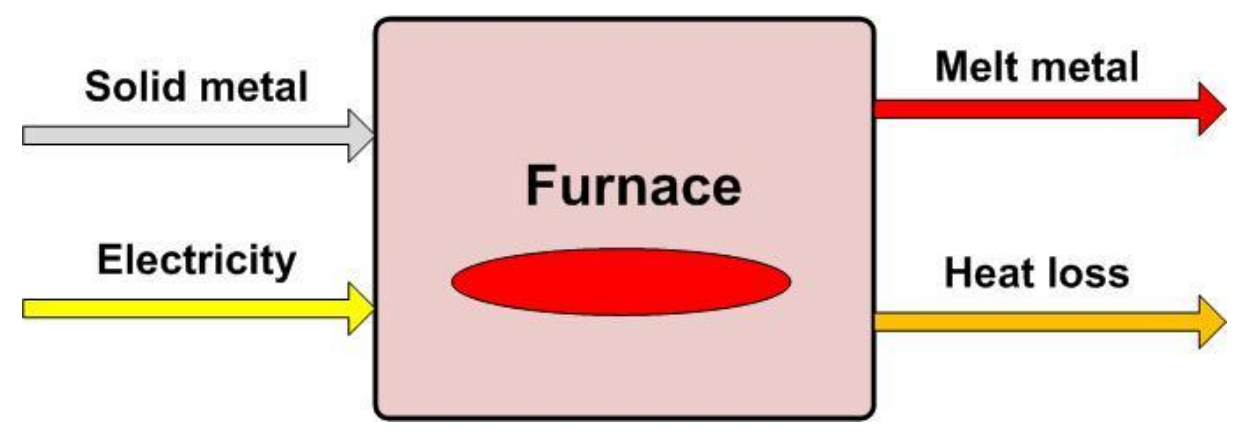

Figure 6 Schematic of energy balance in the induction furnace of CRIMSON.

It should be clarified here that the conventional foundry normally is supplied with the aluminium ingot with trapezoidal cross section came from the primary industry. The quality of this kind of ingot is usually poor due to the harsh and turbulent flow behaviour of melt during the primary production process. The new process requires the billet with circular cross section and in good quality in order to better suit for the crucible of the induction furnace in the new process. At current stage, it is impossible for the suppliers to provide this type of billet due to the small amount of requirements. However, after contacting several suppliers of the direct chill billet in UK, it is possible for them to provide the circular cross section billet with required diameters and sound quality if the ordered amount is proper. The compromising method in this project is that the scrape and ingot are remelted and recast into circular shape with required chemical compositions. The energy consumption occurred due to remelting and recasting is not audited in this paper. 


\section{Experiment results and discussion}

The energy consumption at G\&W where the Cosworth process is applied was investigated where both gas (propane) and electricity are included and the usages are recorded in Table 1. It should be noticed that power measurement may be connected with the day or night rate. During the investigation, only the energy consumption ( $\mathrm{kJ} . \mathrm{kg}_{-}{ }^{1}$ or $\mathrm{MJ}_{\mathrm{kg}}{ }^{-1}$ ) is measured and the cost which linking with the rate is not considered.

\begin{tabular}{|l|l|l|l|}
\hline Energy type & Energy consumption & Energy density by mass $\left({\left.\mathrm{MJ} . \mathrm{kg}^{-1}\right)}^{-1}\right.$ & \\
\hline LPG (propane) $[10]$ & $\left(0.7 \mathrm{~m}^{3}\right.$. tonne $\left.\mathrm{e}^{-1}\right) 65.31 \mathrm{~kJ} \cdot \mathrm{kg}^{-1}$ & 49.6 & \\
\hline Electricity & $\left(2800 \mathrm{kWh} \cdot \mathrm{tonne}^{-1}\right) 10.08 \mathrm{MJ} \cdot \mathrm{kg}^{-1}$ & ------- & \\
\hline
\end{tabular}

Table 1. Actual consumption of gas and electricity in G\&W Ltd where the Cosworth process is applied.

From Table 1, the total actual energy consumption $\Delta E_{A l}$ for melting A354 Al alloys in $\mathrm{G} \& \mathrm{~W}$ can be calculated as $\Delta E_{A l}=44.80 \mathrm{MJ} . \mathrm{kg}^{-1}$.The thermal efficiency of using the LPG for melting the alloys is $\eta_{1}=10.4 \%$. The thermal efficiency of using the electricity for holding the melt is $\eta_{2}=6.14 \%$ [2].

Experimental parameters for casting the "Test bar" mould in the new casting facility are given in Table 2:

\begin{tabular}{|l|l|l|}
\hline Experiment parameter & \multicolumn{1}{|c|}{ Value } & Note \\
\hline Weight of metal charge & $4 \mathrm{~kg}$ & \\
\hline Melt temperature & $729^{\circ} \mathrm{C}$ & Using thermal couple \\
\hline Melting time & 2 minutes & \\
\hline Injection time of Up-caster & 10 Seconds & \\
\hline Holding time & 20 Seconds & \\
\hline Solidification time for & 28 Seconds & \\
\hline $\begin{array}{l}\text { Measured energy consumption } \\
\text { melting the charge }\end{array}$ & $(2.2 \mathrm{KWh})$ & \\
\hline
\end{tabular}

Table 2. Experimental parameters for the "Test bar" in the new casting process facility

The theoretical energy consumption $\Delta E_{A l}^{\prime}$ for heating the A354 alloy to $729{ }^{\circ} \mathrm{C}$ is $\Delta E_{A l}^{\prime}=$ $318 \mathrm{kWh}$. tonne $\mathrm{e}^{-1}$. The energy consumption measured during the melting is 1.98 GJ.tonne- ${ }^{1}$ $\left(550 \mathrm{kWh} \cdot \mathrm{knnn}^{-1}\right)$ (Table 2). The thermal efficiency of the induction furnace can be calculated from these two figures and is $\eta_{c}=57.8 \%$ [2].

The thermal efficiency of the melt furnace at G\&W for gas is $\eta_{1}=10.4 \%$ and for electricity is $\eta_{2}=6.14 \%$. The former $\eta_{1}$ is near the normal thermal efficiency of crucible furnace using gas $(13 \%)$. The later $\eta_{2}$ is far more less than the normal thermal efficiency (59 76\%) of an induction furnace using electricity. This means that there is lot of energy loss for the current melting process at $\mathrm{G} \& \mathrm{~W}$ due to the long holding time. Therefore, it is suggested that if the current long melting and holding process at $\mathrm{G} \& \mathrm{~W}$ could be replaced by the new single 
shot melting method, the thermal efficiency will be increased up to $40 \%$. When melting the same weight of the Al alloys, G\&W used 22.6 times more energy than the new casting facility. It is estimated that 42.8 GJ.tonne $\mathrm{H}^{-1}\left(11.9 \mathrm{MWh}^{\mathrm{M}}\right.$ tonne $\left.{ }^{-1}\right)$ can be saved for producing every tonne of A354 casting alloys when using the new process. Thus, to use the new process, the melting cost will be drastically decreased.

More reasons for recommending the new method instead of using crucible furnace at G\&W are: although a crucible furnace is cheap method for melting Al alloys which is popular in foundry due to its easy for tapping and charging different alloys, the thermal efficiency of the crucible furnace is far lower $(7 \sim 19 \%)$ than the new method $(57.8 \%)$ and the temperature of the liquid alloy is difficult to control. It has been proved in this investigation that the thermal efficiency of furnace at G\&W is only $10.4 \%$. Furthermore, the new method uses a rapid filling method as soon as the alloy is heated to the required temperature, avoiding using holding furnace for holding long time and thus reducing the potential energy wastage. In the mean time, due to the quick melting and filling processes, the opportunity of generating the oxide film on the surface of the liquid alloy and the potential time for hydrogen absorption are drastically reduced. The quality of the casting can be secured accordingly.

\section{Conclusions}

The investigation on melting efficiency of both conventional and new melting processes has revealed that the new method is an innovative method for saving energy in the casting industry. If the conventional foundries could use the novel melting method instead of their traditional melting method, the estimated energy savings could be of the order of 43 GJ.tonne- ${ }^{1}$ (11.9 MWh.tonne $^{-1}$ ) for A354 alloy. This would drastically reduce the production cost by about $£ 904$ pounds.tonne ${ }^{-1}\left(7.6 \mathrm{p} . \mathrm{kWh}^{-1}\right)$. This could be crucial in the rigorously competitive market of casting industry.

The other issues of the energy efficiency for the foundry will be further considered in the next stage of the project where not only the melting process is included, other relevant processes should be considered too.

\section{Acknowledgements}

This research project is funded by the Engineering and Physical Sciences Research Council (EPSRC) of the UK under the grant of EP/G060096/1. Many thanks to the University of Birmingham and N-Tec Ltd. for providing the experiment equipment. Acknowledgement will be given to the Grainger \& Worrall Ltd. and Mr. Martin Wood for providing the experimental data of their current production process. 


\section{References}

[1] BSC, Incorporated, Advanced Melting Technologies: Energy Saving Concepts and Opportunities for the Metal Casting Industry, Report, U.S. Department of Energy, 2005.

[2] X. Dai, M. Jolly, Potential energy savings by application of the novel CRIMSON aluminium casting process, Applied Energy (Accepted for publication)

[3] ENERGY CONSUMPTION GUIDE 38, October-1997, Non-ferrous foundries (Second edition), Department of the Environment, Transport and the Regions.

[4] B. Klaasen, P.T. Jones, D. Durinck, J. Dewulf, P. Wollants, B. Blanpain., 2010, Exergy-Based Efficiency Analysis of Pyrometallurgical Processes, Metallurgical and Materials Transactions B, The Minerals, Metal \& Materials Society and ASM International. 21-August-2010.

[5] R. Eppich, R.D. Naranjo., Implementation of Metal Casting Best Practices, Report of U.S. Department of Energy, 2007.

[6] M. Jolly, Energy Saving in the Foundry Industry by Using the "CRIMSON" Single Shot UPCasting Process, 2010 TMS Annual Meeting \& Exhibition, Febuary 14-18, 2010, Seattle, WA.

[7] J. C. Geelin, M. Lovis \& M.R. Jolly, SIMULATION OF TENSILE TEST BARS: DOES THE FILLING METHOD MATTER?, Symposium on Simulation of Aluminum Shape Casting Processing, TMS2006 March 2006, Warrendale, PA, Eds Q. Wang, M.J.M Krane and P.D Le.

[8] T. L, M. Hassan, K. Kuwana, K. Saito, P. King, 2005 Performance of secondary aluminium melting: Thermodynamic analysis and plant-site experiments.

[9] M. A. Rosen, 2009 Exergy-based Analysis and Efficiency Evaluation for an Aluminium Melting Furnace in a Die-casting Plant, Proceedings of the $4^{\text {th }}$ IASME/WSEAS International Conference on ENERGY \& ENVIORMENT (EE'09).

[10] ]-Wikipedia-Energy density: http://webcache.googleusercontent.com/search?q=cache:COLNRICHJmUJ:en.wikipedia.org/wiki/Ene rgy_density+lpg+density\&cd=2\&hl=en\&ct=clnk\&gl=uk\&client=firefox-a 